review of simulation methods is given in chapter 8.

This book fills a gap in the texts on water resources engineering. It deserves to be studied by all graduate students in the water resources field, and should be read by many others in the associated disciplines.

T. O'DONNELL

\section{How Herbicides Work}

Mode of Action of Herbicides. By Floyd M. Ashton and Alden S. Crafts. Pp. 504. (Wiley Interscience: New York and London, February 1973.) $£ 12.50$.

THIS book is a mine of information. It opens with a few general chapters on the economics of weed control and on the classification of herbicides and then proceeds to give brief comparative consideration of factors affecting uptake and translocation of herbicides, on their molecular fate in the plant and on the main kinds of biochemical responses of plants to their presence. This is followed by fifteen chapters, together occupying the greater part of the book, each dealing with a chemically defined group of related herbicides.

Each of these specialized chapters is arranged on a common plan. First, the herbicides themselves are defined and described. Next, their general macroscopic effects on plants are outlined and our knowledge of their uptake and translocation is summarized. Then follow sections on metabolic change of the herbicides in the plant, if any, and on the known biochemical responses of the plant in the period preceding death. This latter is usually the largest section in each chapter. A final section summarises present views on which of the induced biochemical abnormalities are most clearly associated with plant death. Each chapter is provided with a well chosen set of references so that any point of special interest to the reader can be easily followed up.

The modern herbicides are virtually all products of the last thirty years or so; it is really notable how much work has been done on their physiological and biochemical effects. Two main observations can be made on the results of this work. First, it is clear that very few herbicides indeed have a simply definable mode of action, at least in our present state of knowledge. Perhaps the best example of a simple mode of action is that of the nitrophenols; these compounds have been well known to biochemists for a long time as uncoupling agents and it seems that it is indeed this activity which is mainly responsible for their toxicity to plants. At the other extreme, the phenoxyacetic acid hormone-type weed killers induce an enormous number of un. related biochemical responses and we are still, after thirty years research, far from being able to account for their important herbicidal activity.

The second general observation is that it is striking that few, if any, herbicides show a true specificity of action. Selectivity, when it occurs, is often based on crude mechanisms based on differential wettability of leaf surfaces, ease of uptake and translocation or access to root systems. Sometimes a more sophisticated mechanism is involved where selectivity is based on differential capacity to degrade the herbicide to less toxic derivatives. Specificity based on action at a specific site is not known, contrasting in this respect with some of the more selective antibacterial antibiotics.

This is a book which will interest not only the specialist working on herbicides but also many with a more general interest in the action of toxicants on living cells. It is a book that many would like to have as a reference book on their own shelves, but the price is scarcely encouraging.

\section{P. W. BriaN}

\section{Coastal Problems}

The Water's Edge: Critical Problems of the Coastal Zone. Edited by B. H. Ketchum. (Coastal Zone Workshop held 22 May-3 June, 1972, Woods Hole, Massachusetts.) (MIT: Cambridge, Massachusetts and London, 1972.) $£ 1.80 ; \$ 3.95$.

A RECENT review of scientific, economic, social and political problems of coastal zones has been published from MIT-a result of a "workshop" jointly sponsored in 1972 by the US Institute of Ecology and the Woods Hole Oceanographic Institution and supported by NSF (RANN Program) and the Rockefeller Foundation.

As Hollings ${ }^{1}$ has observed of another, similar exercise "the real success of the workshop rests as much with its style of operation as with its substance" but of its method of operation the book gives little clue. Chapters have been prepared by small, presumably editorial, groups, with "contributions from ...." This technique provides a pleasant uniformity of style, but one wonders how much dissension, argument and genuine difference of view has been incorporated.

The report considers, in turn, diverse aspects of coastal zone problems--those arising from cropping biological resources; from non-renewable resources of oil, gas, minerals, gravel ; those posed by growing demands for recreation and amenity; those changes brought by urbanization, industrial development, navigation and waste disposal schemes.

It effectively distinguishes between exclusive uses of the resource (such as aquaculture, or nature reserves), multiple uses (such as water for industry, waste disposal) and displaceable uses (that is, those such as power stations which could be located elsewhere), and sagely observes that the present sad state of many coastal sites is a result of their non-management as much as mismanagement.

From the British standpoint both comparable and contrasting views are indicated. First, the coastal zone is "a band of dry land and adjacent ocean space"-in effect extending over coastal plains, or even whole watersheds, to the edge of the continental shelf and beyond. The United Kingdom concept of coastal areas, by contrast, appears parochial, if more closely focused. Perhaps inevitably, the same conflicts of use emerge in both the USA and UK, and there is the same divisive confusion of land use planning, management and legislative authorities. It becomes a truism that integrated and well-managed use of these areas demands a closely knit, well coordinated, overall agency, vested with suitable powers to make decisions effective, and with the wisdom of a Solomon, to boot.

In a series of far-reaching recommendations the MIT reports calls for: a national coastal zone policy to determine priorities for future uses and to maintain natural ecosystems; a coastal zone task force to develop management schemes and model guidelines for regional and local plans; for revision of legal institutions and procedures to make management more effective; for establishment of coastal zone centres to carry out and coordinate scientific, social and legal research programmes; for a national system of coastal area preserves with closely restricted access, to protect basic genetic stocks.

The problems exposed are those we face nearer home, the ideal solutions much the same as those we would choose: will the Americans be more successful than we in devising a fair, rational and effective scheme of regional control? The cards seem stacked against them: to quote: " $67 \%$ of California's estuarine habitats lost in twenty years"; "of recreational shoreline, $92 \%$ was privately owned"; "booming coastal industry" which includes increased dredging and filling, increased developments in underwater mining and oil extraction.

UK problems of the coastal zone have been considered, in part, by the Royal Commission $^{2}$. The new Regional Water Authorities will be able to tackle some effects of our present disorganization, but will be short on skills and resources in the aquatic field, at least initially, as well as restricted in the scope of their interest. Surely the need is now for the UK to look at wider aspects of coastal zone management. The growing offshore extraction industries and our developing links with other riparian countries bordering coastal waters will present 